\title{
Utilizing Change Leadership Within Social Work Education to Prioritize and Expand Interprofessional Education in a University Setting: A Case Study
}

\author{
Emily L. McCave \\ Laura Mutrie \\ Maya H. Doyle \\ Stephanie Jacobson \\ Amber Kelly
}

\begin{abstract}
Interprofessional education (IPE) is a critical educational component for promoting the quadruple aim of health care. Additionally, interprofessional practice (IP) is included in the Council on Social Work Education's (CSWE) educational standards. Yet, the organizational change required to integrate a social work program within established interprofessional education (IPE) curriculum is challenging given the resources required, such as personnel, time, and ongoing commitment among stakeholders. We present a case study of one MSW program's process for integrating social work within an existing IPE curriculum and formalizing IPE as a focus point programmatically. The Bacharach Approach, a change leadership model, is used to analyze the MSW program's approach to initiating and sustaining this change initiative. Through strategic decision-making and capitalizing on momentum, the MSW program has become a valued partner and leader of IPE endeavors and the MSW program's focus on IPE programmatically has been solidified. Creativity, adaptability, advocacy, and relationship-building are key skill areas that social work educators can draw upon as they navigate organizational and programmatic changes focused on IPE.
\end{abstract}

Keywords: Change leadership, interprofessional education, collaboration, social work education

Interprofessional education (IPE) is recognized as a critical preparatory component for meeting the quadruple aims of health care - enhancing patient experiences, improving population health, reducing costs, and improving the work life of health care providers (Bodenheimer \& Sinsky, 2014; Institute of Medicine, 2015; Interprofessional Education Collaborative [IPEC], 2016; Rubin et al., 2017). According to the Council on Social Work Education's (CSWE) 2015 Educational Policy Accreditation Standards (EPAS), students must demonstrate competency in interprofessional collaboration and teamwork as part of their social work education. While the imperative for developing and providing IPE is clear, the challenge is creating pathways to implement and assess sustainable, high quality IPE given the considerable, yet critical, resources of personnel, time, and space (Rubin et al., 2017). In this article, we offer a case study of one MSW program, detailing the strategies used to initiate and expand the social work presence within existing IPE and to formally prioritize IPE programmatically within the MSW program. The strategies discussed are presented through the lens of the Bacharach Approach for change leadership

Emily L. McCave, PhD, MSW, LMSW, Professor, Department of Social Work, Laura Mutrie, MSW, LCSW, Director of Field Education and Clinical Assistant Professor, Department of Social Work, Maya H. Doyle, PhD, MSW, LCSW, Associate Professor, Department of Social Work, Stephanie Jacobson, PhD, MSW, LCSW, Associate Professor,

Department of Social Work, and Amber Kelly, PhD, MSW, LCSW, Associate Professor, Department of Social Work, Quinnipiac University, Hamden, CT. 
within higher education (Bacharach, 2005, 2006). Considerations and recommendations for other social work educators interested in similar organizational change are provided.

\section{Relevant Literature}

Social workers have long worked in settings with professionals of other disciplines and as part of teams described as multidisciplinary, inter-disciplinary, and most recently, interprofessional (IP, Dane \& Simon, 1991). The World Health Organization (WHO) defines interprofessional collaborative practice as occurring "when multiple health workers from different professional backgrounds provide comprehensive services by working with patients, their families, carers and communities to deliver the highest quality of care across settings" (WHO, 2010, p. 10). Interprofessional practice can exist in almost any setting that provides health or social services, including medical institutions and community practices, behavioral health settings, criminal justice and re-entry agencies, schools, as well as child welfare and aging settings. Zerden et al. (2019) conducted a study of $395 \mathrm{MSW}$ students and field instructors who work as members of integrated interprofessional healthcare teams. More than half reported working with physicians and nurses in hospital settings. Additionally, respondents worked in a variety of communitybased settings and identified a broad array of other professionals "including child protective service workers, speech pathologists, teachers or school administrators, recreation and vocational specialists, and peer-support specialists" (Zerden et al., 2019, p. 3) as members of the integrated interprofessional healthcare teams. Social work professionals are "ideally situated to participate and provide leadership" given the profession's focus on "community involvement, family-centered care, and communication and ethics" (Jones \& Phillips, 2016, p. 26). With social work's ecological and biopsychosocial perspectives, social workers can contribute uniquely to interprofessional practice by recognizing strengths and challenges for clients on the personal, familial, community, and systemic level, while also gaining insight from fellow members of the IP team.

Specific challenges also exist for social workers practicing interprofessionally, including role delineation, diffusion, and expansion; boundary-stretching (or breaking); inflexible hierarchical structures; splitting within interprofessional teams; and personal or systemic communication breakdowns (Kerson, 2004; Oliver, 2013). Social workers must juggle dual identities and potential identity threats between the values, ethics, and theoretical lens of the profession, and their immersion in and identity as part of an interprofessional team, whether it be in a school, a primary care setting, or within a medical specialty like oncology or nephrology (Agresta, 2006; Chatalalsingh \& Reeves, 2014; McNeil et al., 2013). Often a sole practitioner may represent social work within a team or an agency, limiting access to intra-professional support and to discipline-specific supervision (Oliver, 2013). It has been suggested that for physicians and nurses to understand how social work benefits clients, they need more access and co-location with social workers (Ambrose-Miller \& Ashcroft, 2016). A survey by West et al. (2017) revealed that social workers had a self-perception of lower prestige compared to other professions such as medicine, nursing, and pharmacy, which may negatively impact social workers involved in interprofessional practice. While Zerden and colleagues (2019) found 
that the majority of social workers reported feeling supported and valued as members of the interprofessional team, they also found notable barriers for social workers on the IP team. These barriers include professional cultural differences, lack of knowledge by other team members of social determinants of health, lack of training regarding behavioral health for other team members, salary differences that created inequity on the team, reimbursement issues, and lack of adequate space.

While social workers naturally bring their own professional competency to the interprofessional team, it is not a given that they have also developed competency in interprofessional practice, a different knowledge base and skill set. Interprofessional competency can be introduced and practiced via interprofessional education (IPE, Comer \& Rao, 2015; Jones \& Phillips, 2016; Kobayashi \& Fitzgerald, 2017; Zerden et al., 2019), which occurs "when students from two or more professions learn about, from and with each other to enable effective collaboration and improve health outcomes" (WHO, 2010, p. 7). IPEC, created in 2009, was sponsored by the councils for education of pharmacists, nurses, dentists, osteopathic doctors, public health professionals, and medical doctors (IPEC, 2016). Since then more than 60 other professional groups have become involved in the collaboration, including CSWE.

In preparing to be effective members and leaders of such interprofessional care teams, social workers benefit from opportunities to participate in interprofessional education (Zerden et al., 2019). Social work educators must create opportunities for their students to engage with team members from other professions, allowing them to attain the four core competencies for collaborative interprofessional practice: teamwork, shared values and ethics, understanding role and responsibilities, and effective communication (IPEC, 2016). While social work education provides socialization to the profession, there is an additional need for socialization to interprofessional collaboration and communication (West et al., 2017). Despite social work's knowledge base and practice history with group work and teams, practitioners and students often feel inadequately prepared to effectively engage within interprofessional teams (Comer \& Rao, 2015). For clients to receive the best access to services and to have effective treatment and discharge plans, social workers must, in particular, be able to effectively communicate with such teams (Glaser \& Suter, 2016). Interprofessional communication sub-competencies speak to the specific skills necessary for this work, including choosing effective techniques, providing information in easy to understand language, sharing information clearly, listening actively, giving constructive feedback, being respectful, having awareness of one's unique perspective, as well as engaging in team-based patient-centered care (IPEC, 2016).

Work has already been done to map the intersection of the core competencies for interprofessional practice with the EPAS competencies and to articulate naturally occurring opportunities for IPE within social work curriculum (Rubin et al., 2017). Additionally, Comer and Rao (2015) tracked responses of MSW students who were enrolled in an interprofessional group, noting increased self-awareness around the importance in working with others and knowing the social work role within a team, as well as appreciation for gaining real life experience. Crumb and colleagues (2018) studied the effects on social work students who participated in an interprofessional program that provided mental health services to college students. Social work interns, advisors, and college students all reported 
benefiting from the program, with social work interns indicating benefit from by utilizing their social work skills to administer assessments and assist college students with finding resources, while also practicing their group communication skills with other team members. Kobayashi and Fitzgerald (2017) demonstrated that students enrolled in a complex IP curriculum across co-located health programs from three universities found it beneficial to give and receive feedback across disciplines, and to have a platform to practice their skills.

\section{Organizational Change: The Bacharach Approach}

As a focus on integrating IPE within institutions of higher education continues to increase, added pressure may be placed on administrators and program faculty to prepare for both initiating and responding to change efforts to this end. Similarly, as new programs are established, there is pressure to create a presence within existing IPE. In both cases, organizational change is necessary and requires thoughtful and strategic planning. One way to prepare is to draw on organizational approaches for managing change. The Bacharach Approach (Bacharach, 2005, 2006; Coley, 2020) is a model of change leadership that focuses on leaders as change agents within their institutions. The focus of the model is to win support and capitalize on momentum to push forward change efforts. This is done by adhering to four principles: 1) creating an agenda; 2) mapping the political terrain; 3) drawing support to your side; and 4) making things happen. The approach suggests that change is done organically when leaders empower themselves to guide change efforts through creating and sustaining momentum. There are four sources of momentum that can be capitalized upon: a) structural; b) performance; c) cultural; and d) political. The structural source of momentum focuses on promoting and sustaining capacity building, whereas ongoing monitoring and evaluation is the source of performance momentum. The cultural source of momentum is focused on promoting motivation to sustain change efforts and the last source of momentum, political, involves scanning the environment for potential resistance and mobilizing support for the change effort.

\section{The MSW Program in a School of Health Sciences: A Case Study}

Stake (2005) describes how case study methodology allows us to learn what particular qualitative data can be gained from observing a single case, optimizing learning from the case before generalizing further. In this same vein, we describe the unique development and positioning of the MSW program as an agent of organizational change and its key role in IPE development within a larger school of health sciences utilizing the Bacharach Approach. This MSW program is relatively new, now in its $7^{\text {th }}$ year, residing in the Department of Social Work in a School of Health Sciences, which includes several other health programs, including occupational therapy (OT), physical therapy (PT), physician assistant (PA), diagnostic imaging (DI), biomedical sciences (BMS), and wellness/fitness. The School of Health Sciences is also co-located with the Schools of Medicine, Nursing, Law, and Education. The medical school inaugural class and the MSW program inaugural class both entered the university in 2013. Consequently, the potential for creating meaningful IPE activities through partnerships across departments and school is great. 
The university has a Center for Interprofessional Healthcare Education (CIHE), which sponsors IPE activities each semester, and offers students a program of Distinction in Interprofessional Healthcare Education. The distinction program requires completion of 60 hours of IPE activities, online modules and reflections prior to graduation. The CIHE takes responsibility for space planning, distribution of any pre-reading materials, student registration, provision of supplies and/or snacks, and post-activity data collection. While the CIHE has grown significantly over the past several years due to the commitment of faculty across Schools, challenges remain. CIHE has historically received minimal financial support from the university and limited infrastructure exists. Availability of appropriate/adequate space for larger IPE events and conflicting student schedules by program and departments create barriers in planning. An additional unique challenge has been that, with the advent of a new medical school, the university does not have an academic medical center, thus efforts to deliver IPE have been primarily within the academic setting rather than the clinical setting; more elaborate relationship-building and contractual agreements are necessitated with clinical and field learning sites.

\section{Creating an Agenda}

Given the unique academic context described above, the MSW faculty chose to explicitly highlight interprofessional education as a primary focus within the program, thereby setting the agenda for initiating a social work presence within the university's existing interprofessional education curriculum. This initially started by including language within its mission statement and program goals. The mission of "the MSW Program is to prepare social workers for specialized practice in the context of health and behavioral health settings through a curriculum that focuses on clinical practice, organizational practice, and interprofessional [emphasis added] teamwork....". One of the MSW Program's four program goals includes a focus on interprofessional practice, to "prepare social workers to engage in professional activities that promote interprofessional [emphasis added] collaboration and advocacy within diverse environments toward the enhancement of the human condition". By including this language in both the mission statement and within one of the program goals, the MSW Program has a clear rationale and justification for not only initiating integration within existing IPE but also centering IPE as part of the explicit social work curriculum.

\section{Mapping the Political Terrain}

As a new program within the School of Health Sciences, it was necessary to explore the extent to which social work was a welcome new addition within existing IPE and what potential barriers might be encountered. To facilitate this understanding, MSW faculty participated in various meetings with program leaders and faculty within the other departments in the School as well as in the other schools co-located on campus in order to provide information about the MSW program and communicate an interest in collaboration for IPE. Additionally, MSW faculty joined the IP Planning Committee organized by the CIHE Director as a way to foster connections and learn about existing IPE as well as new IPE initiatives and opportunities. Fortunately, the terrain was such that the idea of creating a social work presence within existing IPE was very much appreciated from nearly all 
programs. The initial barrier was the lack of awareness that the MSW program existed, particularly as the program was within the College of Arts and Sciences for its inaugural year and housed on a different campus. Despite the social work department having moved, both physically and structurally, within the School of Health Sciences, the dissemination and internalization of that fact was slow. Another barrier that arose was differing academic and clinical/fieldwork schedules of students and faculty from different programs. Social work, as the newest player, required additional accommodation to demonstrate involvement and gain credibility within a context that already included ongoing challenges for programs already engaged in IPE. Consequently, over the next few years, the MSW program became recognized as both an eager and valuable partner across schools.

More recently the political terrain has shifted as upper leadership within the university has changed, including both the Provost and the President. In 2018, the President launched a new university strategic plan, with its first goal being "build an institution-wide mindset that prepares graduates for 21st-century careers and citizenship" (Quinnipiac University, 2019 , p. 9). Interprofessional competency is truly part of workforce development in social work, particularly for students in an MSW program focused on roles in health and behavioral health settings. While dips in enrollment have been seen by undergraduate and graduate programs across disciplines nationally (McFarland et al., 2019; Okahana \& Zhou, 2018), the health sciences remain one of the fasting growing areas of employment. The U.S. Bureau of Labor Statistics projects that social work jobs will grow by $11.5 \%$ between 2014 and 2024 (Salsberg et al., 2017). In a competitive marketplace, providing a strong interprofessional education component can be an important selling point for attracting students to university programs. Generating buy-in from the university and the schools of Health Science, Nursing, Medicine, Law, and Education has been essential to the growth of IPE activities and the integration of social work within these activities.

\section{Drawing Support to Your Side}

Given that the MSW program is not an independent school, but rather housed within the School of Health Sciences, it was important to draw on support at the school level for both integrating social work into existing IPE activities and centering IPE within the MSW program. One way in which this support was garnered was reminding the various program leaders in the school that the importance of interprofessional education and practice was explicitly in the mission and values statement of the School of Health Sciences, which "offers a student-centered learning environment with interprofessional collaboration, innovative teaching and hands-on experience" and "values an interprofessional, client/patient-centered health care model and the translational science that supports it" (Quinnipiac University School of Health Sciences, 2018, p. 2). Having written language at the school level supports faculty across departments as they consider whether their time and energy put into IPE will be recognized.

\section{Making Things Happen}

Over the past six years, the MSW faculty increasingly became involved with IPE activities based on their areas of expertise and interest. Initially, MSW faculty joined existing IPE activities, bringing in a social work perspective. From there, MSW faculty 
began developing new IPE activities where social work has a major role to play along with other health professionals. Despite only having six full-time faculty in the MSW Program, there has been a high level of participation in IPE events, with consistent requests from the CIHE and faculty from other schools and departments for social work faculty and student representation in IPE activities. By having faculty participate in such events, they model the importance of interprofessional practice for MSW students and can better encourage students to participate beyond the program requirements. Table 1 highlights the breadth of IPE activities that MSW faculty have been involved with and that meaningfully integrate social work students with interprofessional core competencies for each activity noted.

\section{Creating and Sustaining Momentum}

\section{Structural Momentum}

Maintaining capacity for continued change requires significant resources, both in terms of time and money. One way this has been negotiated by the MSW program is to seek out or participate in grant funded IPE activities. The Scholarship of Teaching and Learning Program (SoTL) offers small grants for projects focused on testing innovative teaching methods and producing scholarship. One MSW faculty member received two consecutive SoTL grants, both focused on game-based IPE learning. One used a strategy board game to promote interprofessional practice (McCave, Winter 2016) and the other entailed designing an escape room focused on teaching the core competencies for interprofessional practice. Another MSW faculty member received an internal global education grant to create an interprofessional credit-bearing course on trauma-informed practice for healthcare professionals, in coordination with local partners in Barbados.

Capitalizing on external funding, one MSW faculty member has been involved with the CIHE's Low Vision Clinic, which was started with a community grant from the Lion's Club. The Low Vision Clinic (Meriano \& Mutrie, 2016, March 5) is an innovative interprofessional clinic that operates at no cost to clients. It is offered one afternoon a week and provides occupational therapy (OT) vision evaluations and assistive technology to clients. Clients are self- referred or referred by their community health care providers. The MSW faculty member offers social work assessments and a monthly social and emotional support group for clients and their caretakers/partners. Each year, social work students are offered the opportunity to observe the support group and one student participates annually as full member of the team eventually completing assessments, following up on needs that clients have expressed, and consulting with OT faculty and students to provide quality, coordinated care and support. OT faculty have expressed the value of having the social work perspective represented, especially as it relates to the full bio-psycho-social-spiritual assessment of the clients who are often grieving not only the loss of vision but also a loss of independence, and experiencing the complications of multiple health and personal changes. 
Table 1. Sample of IPE Activities Offered Involving Social Work Faculty and Students

\begin{tabular}{|c|c|c|c|c|}
\hline Event Title & Topic(s) & SW Role & Timeframe/ Format & IPEC Competencies* \\
\hline $\begin{array}{l}\text { Holistic Healthcare for } \\
\text { Transgender Patients } \\
\text { (McCave et al., 2019) }\end{array}$ & $\begin{array}{l}\text { - Gender identity } \\
\text { - Chronic Health Condition } \\
\text { - Healthcare Disparities } \\
\text { - Workplace Discrimination }\end{array}$ & $\begin{array}{l}\text { Lead developer, } \\
\text { coordinator, } \\
\text { facilitators }\end{array}$ & 4-hour workshop & $\begin{array}{l}\text { - Teamwork } \\
\text { - Ethics \& values } \\
\text { - Roles } \\
\text { - Communication }\end{array}$ \\
\hline $\begin{array}{l}\text { Josh's Journey } \\
\text { (Cordeau et al., 2017; Jacobson \& } \\
\text { Mutrie, 2014, October 23-26) }\end{array}$ & $\begin{array}{l}\text { - Oncology } \\
\text { - Hospice } \\
\text { - End-of-Life } \\
\text { - Adolescence }\end{array}$ & $\begin{array}{l}\text { Lead developer IPE } \\
\text { event coordinator, } \\
\text { facilitator }\end{array}$ & 3 hours & $\begin{array}{l}\text { - Roles } \\
\text { - Communication }\end{array}$ \\
\hline $\begin{array}{l}\text { Harm Reduction for Healthcare } \\
\text { Providers }\end{array}$ & $\begin{array}{l}\text { - Addiction } \\
\text { - Harm Reduction } \\
\text { - Chronic Health Condition } \\
\text { - Homelessness } \\
\text { - Trauma }\end{array}$ & $\begin{array}{l}\text { Lead developer, } \\
\text { liaison with } \\
\text { community coalition }\end{array}$ & 5-hour seminar & $\begin{array}{l}\text { - Teamwork } \\
\text { - Communication }\end{array}$ \\
\hline $\begin{array}{l}\text { Simulation of an Interprofessional } \\
\text { Pupil Team } \\
\text { (Richards et al., 2019, Oct 20-23) }\end{array}$ & $\begin{array}{l}\text { - School } \\
\text { - Individualized Education } \\
\text { Planning } \\
\text { - Chronic/Rare Health Condition } \\
\text { - Disability }\end{array}$ & $\begin{array}{l}\text { Developer, } \\
\text { Facilitator, speaker }\end{array}$ & 2 hours & $\begin{array}{l}\text { - Teamwork } \\
\text { - Communication }\end{array}$ \\
\hline $\begin{array}{l}\text { Compassionate Interprofessional } \\
\text { Care for a family impacted by ALS }\end{array}$ & $\begin{array}{l}\text { - Chronic Health Condition } \\
\text { - Addiction } \\
\text { - End of Life } \\
\text { - Bias } \\
\text { - Legal issues }\end{array}$ & $\begin{array}{l}\text { Developer, } \\
\text { facilitators, roleplay }\end{array}$ & 1.5 -hour case study & - Values \& Ethics \\
\hline $\begin{array}{l}\text { Veterans Interview: What, When, } \\
\text { Why and How it Can be } \\
\text { Interprofessional }\end{array}$ & $\begin{array}{l}\text { - Veterans } \\
\text { - Housing } \\
\text { - Health Conditions }\end{array}$ & $\begin{array}{l}\text { Co-developer, MSW } \\
\text { student speaker }\end{array}$ & 1.5 hours & $\begin{array}{l}\text { - Values \& Ethics } \\
\text { - Roles } \\
\text { - Communication }\end{array}$ \\
\hline The Cardiac Journey & - Health Condition & $\begin{array}{l}\text { Co-developer, } \\
\text { facilitator, speaker }\end{array}$ & 2.5-hour seminar & $\begin{array}{l}\text { - Teamwork } \\
\text { - Communication } \\
\end{array}$ \\
\hline
\end{tabular}




\section{Performance Momentum}

Over the past seven years, the MSW program has monitored and made adjustments to the way in which IPE is integrated into the explicit social work curriculum. At its inception, the MSW program included a required generalist course on interprofessional education as it related to special topics of interest, such as end of life care, public health social work, and adult trauma. This course exposed students to readings on the importance of interprofessional practice, the role of the social work profession within the health/behavioral healthcare team, and the roles and responsibilities of other professions typically involved given the course topic. Guest speakers were routinely brought in to highlight this latter aspect. The course required a reflection paper on students' developing professional identity not only as a social worker (i.e., uniprofessional identity) but also as an interprofessional practitioner. This assignment also required students to connect interprofessional practice to social work values and ethics. As faculty became more integrated into the larger university system and involved with CIHE, the course evolved to include a requirement to attend two CIHE-sponsored IPE events. The reflection paper then was able to move from a more theoretical reflection to one grounded on recent interprofessional practice experiences. The faculty chose the two IPE events for students to attend, both of which had a critical role for social work students. Of note, this course was open to graduate students outside of the MSW Program, with medical students enrolling on occasion.

While there certainly were benefits to this course, there was also a significant limitation that led the MSW program to make a shift in the curriculum. For most of the classroom experience, MSW students did not get the benefit of learning from and by peers in other health professions, a necessary element of IPE, aside from the two required events. While listening to a guest speaker from another profession is certainly beneficial, it does not meet the definition of interprofessional education, according to IPEC (2016), unless there is ample time for students to engage in discussion with their peers from other health professions.

Given this limitation, after six years of offering the course, the MSW faculty decided to remove the required course and instead require all students to complete a certain number of IPE activities prior to graduating. Each student is required to log in their completed IPE activities using an online platform, which is also used to track field hours. Advisors are required to monitor their advisees progress each semester. During the generalist curriculum, all students are required to complete four interactive online modules offered by the CIHE, which provide a solid foundation on the core competencies of interprofessional practice. Each module takes around 60-90 minutes to complete. Generalist students are required to participate in a specific IPE event, called Holistic Healthcare with Transgender Patients (McCave et al., 2019) as well as attend one CIHEsponsored event of their choice. Specialized students are required to serve as facilitators for the Holistic Healthcare with Transgender Patients IPE event and then choose two other CIHE-sponsored events to attend. For the Advanced Standing Program, specialized students are required to complete the online modules, attend the Holistic Healthcare with Transgender Patients IPE event, and attend one CIHE-sponsored event of their choice. Students in the Traditional MSW Program will complete 20-25 hours of IPE activities by 
graduation, while Advanced Standing students, on an accelerated track through the program, will complete 10-12 hours. All students can choose to complete 60 hours for IPE Distinction at graduation, but this is more easily accomplished by undergraduates, in comparison to MSW students tasked with academic work and 16-24 hour/week field placement schedules. The reconfiguration of the MSW IPE course into the larger offerings of the CIHE provides greater opportunity for students to undertake activities that meet their interest and practice needs and frees faculty course loads for other program needs and other IPE development. On several occasions, IPE activities have been piloted in specialization year elective classes, before being scaled up for a full CIHE-sponsored activity.

\section{Cultural Momentum}

IPE has become a part of the culture of faculty scholarship within the social work department, as well as an explicit part of the MSW curriculum. A motivating factor for development of and participation in IPE by social work faculty is its inclusion within the promotion, tenure, and review process within MSW Program. One of the ways in which the MSW faculty have been able to increase their involvement in IPE learning activities is by having it explicitly supported by department and school leadership. IPE projects (see Table 1) have been included as MSW faculty move through review, promotion, and tenure processes, and are also included with annual faculty workload plans. The MSW faculty have been able to consider their participation in IPE events as service, whether it be serving on a committee to develop an IPE event, and/or facilitating discussion, providing a social work perspective, taking part in a roleplay, or being a panel speaker during an IPE learning activity. Additionally, MSW faculty have made it a priority to gather data and disseminate their IPE work as scholarship through publications (Cordeau et al., 2017; Hughes et al., 2020; McCave, Winter 2016; McCave et al., 2019) and presentations (DeFrancesco et al., 2015, Feb 26-March 1; Hartmann et al., 2017, Oct 1-4) at the state, national, and international level.

\section{Political Momentum}

As MSW faculty increased their involvement with IPE across the university, there was recognition that, politically, the MSW program could capitalize on IPE leadership opportunities, to mobilize support for growth and scan for potential political obstacles and opportunities at various administrative levels across the university. Two particular opportunities arose. First, as CIHE began to grow, there was a recognition that sustainability required a pipeline for faculty development in IPE. This was done through the creation of the Center's IP Fellows program. This two-year program involved having each of the Deans from the three health schools appoint an IP Fellow from their school. Each IP Fellow receives targeted training in IPE offered by an external organization (such as the Nexus T3 Interprofessional Team Development Program), serves as a liaison to their School, and focuses on a year-long IPE project. The first IP Fellow for the School of Health Sciences appointed was an MSW faculty member. When additional funding became available for the first Assistant Director of the CIHE, that same MSW faculty member applied and was appointed by the three Deans. In this role, the MSW faculty member served as a liaison with all three health schools and their respective programs and was a 
part of high-level discussions with deans, the provost, as well as the university president as it related to IPE at a university level.

\section{Recommendations for Social Work Educators}

There is no one "right" method for approaching integration of social work into existing IPE or prioritizing IPE within social work education. Utilizing an organizational change theory or model, such as the one discussed in this article, can be beneficial for approaching a change effort such as this in an intentional manner. Insight into theories of change and change leadership can be helpful in understanding and building strategy on multiple levels, such as department, school, and university, when integrating and expanding IPE.

Further, exploring the literature for how differing universities approach the work is key. Jones and Phillips (2016) provide a number of examples of social work interprofessional programs and the roles of social work in interpersonal education at several universities, asserting that IPE must be part of social work's educational preparation. They suggest strategies that expand the commonly used case example style for IPE group activities to include dialogue with and shadowing of other members of the healthcare team during fieldwork, interprofessionally co-taught courses, IP curriculum development, interdisciplinary team-based course assignments, and more. In this case study, success has occurred in large part due to creativity, adaptability, advocacy, and relationship-building. These skill areas may be worth consideration by other social work educators who wish to embark on a similar change effort. Although every context is unique, those social work programs whose size is relatively small (i.e., < 100 students and $<10$ full-time faculty) and that are part of a larger interprofessional school may benefit from engaging in similar approaches to that undertaken by this program.

\section{Creativity}

Joining existing IPE requires that social work educators think creatively as to how to meaningfully integrate social work in a way that is not an afterthought. Given that IPE activities are often highly structured, particularly those that are case-based, social work educators need to present potential modifications as an opportunity to enhance the current activity and do so in a collaborative manner with those who initially created the activity and/or those who are currently implementing the activity. This requires out of the box thinking, particularly when an IPE activity has been implemented successfully for some time and there are reservations about making changes. Similarly, creative thinking is required for developing new IPE activities that place social work along with other health professions at the center, rather than the periphery, of the learning experience. MedEd Portal is a valuable resource for social work educators, as it has a special IPE Collection that provides open-source IPE material for use and adaptation focused on a variety of health and behavioral health issues.

One way to stimulate this creative thinking is to utilize existing structures that offer time for collaboration and reflection. For example, many universities require or offer faculty development trainings throughout the year. Inviting presenters who can energize faculty about IPE development can be particularly fruitful as well as carving out time for 
faculty across programs to reexamine current IPE activities and consider new opportunities.

Social work educators can also be creative as to how IPE is prioritized internally. As discussed in this article, this MSW program made changes to its curriculum, established IPE requirements for students, and integrated IP language in the mission, goals, and within promotion and tenure guidelines. There are many paths to formally recognizing IPE as a valued component of social work education. Through monitoring and evaluation, social work programs can adeptly decide which path may lead to more success.

Once IPE and social work education is integrated within the academic setting, future aspirations can be to adapt and integrate IPE learning activities into field education settings where interprofessional practice is likely occurring, such as hospitals, schools, nursing homes or palliative care settings, so that students can learn alongside agency staff and supervisors. Well established IPE learning activities could be brought to agencies, thus providing field agencies with helpful staff development opportunities for both staff as well as student interns. Offering such staff development could be an additional benefit to agencies hosting field placements, particularly if continuing education units (CEUs) could be provided to agency staff. Assessment of interprofessional competencies can also be incorporated into field evaluation.

\section{Adaptability}

It is critical that social work educators are both adaptive and responsive to shifting landscapes, whether the change comes from the broader landscape of social work education (e.g., changing accreditation standards) or higher education (e.g., changing enrollment and demographics). Political terrains and institutional priorities can shift with both anticipated and unanticipated changes in program, school, or university level leadership. Social work educators need to navigate such changes using political savviness and drawing on knowledge and skills many already possess as a consequence of their own social work education and practice experiences (e.g., using SWOT analyses).

Further, social work educators may need to adapt when long time IPE partners are no longer available, whether they be faculty from other programs, community partners, or others. There may be times that social work faculty need to "carry" the IPE activity or initiative until new partners can be identified and fully integrated. In such times, it is beneficial for the social work leadership to recognize this extra work and adapt existing workload responsibilities if possible.

\section{Advocacy}

Integrating social work faculty and students into existing IPE activities and prioritizing IPE within social work education requires advocacy both within and beyond the program. For social work educators who are new to IPE or whose departments are unfamiliar with IPE development, it can be helpful to have an "IPE champion" who is willing to dive into the literature, seek out training and professional development, and bring back what has been learned to both the social work program and other health programs. Social work educators who are in departments where there is resistance to devoting already stretched 
resources to IPE may find it beneficial to refer to both the EPAS standards and also the 2019 report issued by the National Center for Interprofessional Practice and Education (IPEC) and the Health Professions Accreditors Collaborative (HPAC) entitled Guidance on Developing Quality Interprofessional Education for the Health Professions (HPAC, 2019). It is notable that CSWE made significant contributions to this report. This formalized recognition of the importance of IPE for health professions can be used as an effective advocacy tool at multiple levels (i.e., program, school, university).

\section{Relationship-Building}

Integrating social work within IPE requires significant time dedicated to relationshipbuilding, particularly as a new program; fortunately, as social workers, this is an existing skill set can be easily tapped. Setting aside time for multiple face-to-face meetings with those who may be potential partners is critical - one lesson learned is that only communicating via email can lead to miscommunication, confusion regarding expectations, and a limited understanding of the value that each discipline has to offer. The potential for miscommunication was heightened at the outset of the Covid-19 pandemic, as IPE events involving multiple stakeholders had to be cancelled with little notice. In such challenging circumstances, communicating in a timely and responsive manner, often via virtual meetings, was critical for moving forward. Heading into a new academic year in which IPE will be primarily delivered virtually will itself require collective interprofessional work to meet student needs.

Another way in which relationship-building is important is through commitment to creating sustainable IPE activities and initiatives. Connecting faculty who have shared interests and expertise and cultivating those relationships can assist with creating and sustaining momentum for IPE activities that require a significant amount of time and energy. Lastly, as new social work faculty are hired and brought into the social work program, it is essential that existing faculty connect them with current IPE partners while also capitalizing upon external relationships that the new faculty may have that could be incorporated into the IPE curriculum.

\section{Future Directions}

While the value of interprofessional education, practice, and collaboration is widely recognized, the evidence base for its effectiveness remains somewhat limited (Reeves et al., 2017; Zwarenstein \& Bryant, 2000; Zwarenstein et al., 2009). This is primarily due to few randomized trials, lack of longitudinal evidence, and a narrow selection of source countries economically and geographically. This limitation also exists for this MSW program as well. Effective data collection and evaluation has been identified as the next priority as there has not been a process put in place to evaluate the impact for social work students specifically. While all students participating in IPE activities complete surveys disseminated through the CIHE, the data gathered is cross-sectional, focused solely on the IP competencies, and is presented at the aggregate rather than at the program level. This MSW program is interested in the impact of IPE not just immediately following the activity, but in the potential impact in field education and in future practice after graduation. Social work educators have the potential to contribute evidence regarding the 
overall effectiveness and positive outcomes of interprofessional collaboration across health professions. Longitudinal data collection specific to social work is an important goal, whether gathered from students over their time of coursework, across student cohorts, or from MSW alumni providing data about the impact of IPE on their current practice following graduation.

\section{Conclusion}

While social workers are no strangers to working with other disciplines and on interprofessional teams, there is a growing need for targeted social work education centered on promoting competency for collaborative interprofessional practice. Such interprofessional practice is essential for our students to go on to provide high quality care. Additionally, acquiring competency in interprofessional practice has the potential to reduce burnout and role strain while providing much needed support to social workers. Creativity, adaptability, advocacy, and relationship-building are skills that can be capitalized upon for successful integration of IPE into social work education and to integrate social work faculty and students into IPE. Social work is a profession that often utilizes many of these same skills in daily professional practice and is thus uniquely positioned to be at the forefront of IPE development and sustainability. Through intentional planning and purposeful engagement with university and community partners, social work educators can skillfully respond to the need for social work representation in IPE while modeling the importance of interprofessional practice and leadership to the next generation of social workers.

\section{References}

Agresta, J. (2006). Job satisfaction among school social workers. Journal of Social Service Research, 33(1), 47-52. https://doi.org/10.1300/J079v33n01_05

Ambrose-Miller, W., \& Ashcroft, R. (2016, May). Challenges faced by social workers as members of interprofessional collaborative health care teams. Health Social Work, 41(2), 101-109. https://doi.org/10.1093/hsw/hlw006

Bacharach, S. B. (2005). Get them on your side. Simon and Schuster.

Bacharach, S. B. (2006). Keep them on your side: Leading and managing for momentum. Simon and Schuster.

Bodenheimer, T., \& Sinsky, C. (2014, Nov-Dec). From triple to quadruple aim: Care of the patient requires care of the provider. Annals of Family Medicine, 12(6), 573-576. https://doi.org/10.1370/afm.1713

Chatalalsingh, C., \& Reeves, S. (2014). Leading team learning: What makes interprofessional teams learn to work well? Journal of Interprofessional Care, 28(6), 513-518. https://doi.org/10.3109/13561820.2014.900001

Coley, T. (2020). Change leadership models and methods. Ellucian. https://www.ellucian.com/insights/change-leadership-models-and-methods 
Comer, E., \& Rao, S. (2015). Transforming social group work learning into competencies for interprofessional teams. Social Work with Groups, 39(1), 62-75. https://doi.org/10.1080/01609513.2015.1013172

Cordeau, M. A., Rogers, D., Brown, D. J., Glynn, B., Gray, M. B., Grgurich, T., Herbst, J. L., Kasinskas, C., Lewis, M. A., Mutrie, L., Myrick, K. M., \& Van Oss, T. (2017). Interprofessional end of life care of a teenager. In S. H. Campbell \& K. Daley (Eds.), Simulation scenarios for nursing educators: Making it real (3rd ed., pp. 445-456). Springer Publishing Company. https://doi.org/10.1891/9780826119391.0038

Council on Social Work Education. (2015). 2015 Educational Policy Accreditation Standards for baccalaureate and master's social work programs. CSWE. https://www.cswe.org/getattachment/Accreditation/Accreditation-Process/2015EPAS/2015EPAS_Web_FINAL.pdf.aspx

Crumb, L., Larkin, R., Johnson, M., Smith, J., Howard, A., \& Glenn, C. T. (2018). An interprofessional internship model for training master's level social work and counseling students in higher education settings. Journal of Human Behavior in the Social Environment, 28(8), 1091-1096. https://doi.org/https://doi.org/10.1080/10911359.2018.1470952

Dane, B. O., \& Simon, B. L. (1991). Resident guests: Social workers in host settings. Social Work, 36(3), 208-213. https://doi.org/10.1093/sw/36.3.208

DeFrancesco, E., Bedard, L., Nicholson, N., Jacobson, S. A., \& Hodgson, L. (2015, Feb 26-March 1). Lessons learned from Quinnipiac University's inaugural interprofessional healthcare in aging leadership academy [Conference session]. Association of Gerontology in Higher Education Annual Meeting, Nashville, TN.

Glaser, B., \& Suter, E. (2016, May-Jun). Interprofessional collaboration and integration as experienced by social workers in health care. Social Work in Health Care, 55(5), 395-408. https://doi.org/10.1080/00981389.2015.1116483

Hartmann, K., Bernard, A., Copes, L., McCave, E., \& Myrick, K. (2017, Oct 1-4). Developing a sustainable model for institutionalizing interprofessional healthcare across pre-professional programs: A complex leadership paradigm [Conference session]. Collaborating Across Borders VI: Exploring New Heights, Banff, Canada.

Health Professions Accreditors Collaborative. (2019). Guidance on developing quality interprofessional education for the health professions. HPAC.

https://healthprofessionsaccreditors.org/wpcontent/uploads/2019/02/HPACGuidance02-01-19.pdf

Hughes, M., Macica, C., Meriano, C., \& Doyle, M. (2020). Giving credence to the experience of X-linked hypophosphatemia in adulthood: An interprofessional mixedmethods study. Journal of Patient-Centered Research and Reviews, 7(2), 176. https://doi.org/https://doi.org/10.17294/2330-0698.1727 
Institute of Medicine. (2015). Measuring the impact of interprofessional education on collaborative practice and patient outcomes. National Academies Press.

https://doi.org/10.17226/21726

Interprofessional Education Collaborative. (2016). Core competencies for interprofessional collaborative practice: 2016 update. https://nebula.wsimg.com/2f68a39520b03336b41038c370497473?AccessKeyId=DC 06780E69ED19E2B3A5\&disposition=0\&alloworigin $=1$

Jacobson, S. A., \& Mutrie, L. (2014, October 23-26). Interprofessional simulation: Moving beyond role play in education, field instruction, and supervision [Roundtable discussion]. Council on Social Work Education Annual Program Meeting, Tampa, FL.

Jones, B., \& Phillips, F. (2016). Social work and interprofessional education in health care: A call for continued leadership. Journal of Social Work Education, 52(1), 1829. https://doi.org/10.1080/10437797.2016.1112629

Kerson, T. S. (2004). Boundary-spanning. Social Work in Mental Health, 2(2-3), 39-57. https://doi.org/10.1300/J200v02n02 04

Kobayashi, R., \& Fitzgerald, C. (2017). Teaching note-asserting social work's role in developing an interprofessional education project. Journal of Social Work Education, 53(4), 737-743. https://doi.org/10.1080/10437797.2017.1284627

McCave, E. L. (Winter 2016). Teaching interprofessional practice skills by "Saving Humanity": An innovative IPE curricular method using a cooperative strategy board game. Collaborative Health Care: Interprofessional Practice, Education, and Evaluation Newsletter, 7(2), 5-7. https://www.jefferson.edu/content/dam/tju/JIEC/files/JCIPENewsletter FINAL PDF.pdf

McCave, E. L., Aptaker, D., Hartmann, K., \& Zucconi, R. (2019). Promoting affirmative transgender healthcare practice within hospitals: An ipe standardized patient simulation for graduate healthcare learners. MedEdPortal: The Jopurnal of Teaching and Learning Resources, 15, 1-10. https://doi.org/10.15766/mep_2374-8265.10861

McFarland, J., Hussar, B., Zhang, J., Wang, X., Wang, K., Hein, S., Diliberti, M., Cataldi, E. F., Mann, F. B., \& Barmer, A. (2019). The condition of education 2019. NCES 2019-144. National Center for Education Statistics. https://nces.ed.gov/pubs2019/2019144.pdf

McNeil, K. A., Mitchell, R. J., \& Parker, V. (2013). Interprofessional practice and professional identity threat. Health Sociology Review, 22(3), 291-307. https://doi.org/10.5172/hesr.2013.2951

Meriano, C., \& Mutrie, L. (2016, March 5). Creating an interprofessional Lion's Low Vision Clinic: A short course [Conference session]. Connecticut Occupational Therapy Association Annual Conference, Cromwell, CT. 
Okahana, H., \& Zhou, E. (2018). Graduate enrollment and degrees: 2007 to 2017. Washington, DC: Council of Graduate Schools. https://cgsnet.org/publicationpdf/5464/CGS_GED17_Report.pdf

Oliver, C. (2013). Social workers as boundary spanners: Reframing our professional identity for interprofessional practice. Social Work Education, 32(6), 773-784. https://doi.org/10.1080/02615479.2013.765401

Quinnipiac University. (2019). Strategic plan for Quinnipiac University. https://www.qu.edu/content/dam/qu/documents/strategic-plan-quinnipiacuniversity.pdf

Quinnipiac University School of Health Sciences. (2018). Strategic plan 2018-2021. [Internal report].

Reeves, S., Pelone, F., Harrison, R., Goldman, J., \& Zwarenstein, M. (2017). Interprofessional collaboration to improve professional practice and healthcare outcomes. Cochrane Database of Systematic Reviews, 6(6), 1-38. https://doi.org/10.1002/14651858.CD000072.pub3

Richards, C., Mutrie, L., \& Booth, J. (2019, Oct 20-23). Use of Planning and Placement Team meeting simulation to teach interprofessional collaboration in a school-based setting and beyond [conference session]. Collaborating Across Borders VII: Crossroads of Collaboration, Indianapolis, IN.

Rubin, M., Cohen Konrad, S., Nimmagadda, J., Scheyett, A., \& Dunn, K. (2017). Social work and interprofessional education: integration, intersectionality, and institutional leadership. Social Work Education, 37(1), 17-33. https://doi.org/10.1080/02615479.2017.1363174

Salsberg, E., Quigley, L., Mehfoud, N., Acquaviva, K. D., Wyche, K., \& Silwa, S. (2017). Profile of the social work workforce: A report to the Council on Social Work Education and National Workforce Initiative steering committee. https://www.socialworkers.org/LinkClick.aspx?fileticket=wCttjrHq0gE\%3D

Stake, R. E. (2005). Qualitative case studies. In N. K. Denzin \& Y. S. Lincolen (Eds.), The Sage handbook of qualitative research (3rd ed., pp. 443-466). Sage Publications Ltd.

West, A., Miller, S., \& Leitch, J. (2017). Professional socialization and attitudes towards interprofessional collaboration among graduate social work and health professions students. Advances in Social Work, 17(2), 134-150. https://doi.org/10.18060/19809

World Health Organization. (2010). Framework for action on interprofessional education and collaborative practice. https://www.who.int/hrh/resources/framework_action/en/

Zerden, L. D., Lombardi, B. M., \& Richman, E. L. (2019). Social workers on the interprofessional integrated team: Elements of team integration and barriers to practice. Journal of Interprofessional Education \& Practice, 17, 1-7.

https://doi.org/10.1016/j.xjep.2019.100286 
Zwarenstein, M., \& Bryant, W. (2000). Interventions to promote collaboration between nurses and doctors. Cochrane Database of Systematic Reviews(2), CD000072. https://doi.org/10.1002/14651858.CD000072

Zwarenstein, M., Goldman, J., \& Reeves, S. (2009). Interprofessional collaboration: Effects of practice-based interventions on professional practice and healthcare outcomes. Cochrane Database of Systematic Reviews(3), CD000072. https://doi.org/10.1002/14651858.CD000072.pub2

Author note: Address correspondence to Emily McCave, Department of Social Work, Quinnipiac University, 275 Mount Carmel Ave., NH-HSC, Hamden, CT, 06517. Email: Emily.mccave@quinnipiac.edu 